\title{
Influence of sample preparation on MX-80 bentonite microstructure
}

\author{
M. MATUSEWICZ*, V.-M. PULKKANEN AND M. OLIN \\ VTT Technical Research Centre of Finland Ltd, P.O. Box 1000, FI-02044 VTT, Finland
}

(Received 31 May 2015; revised 13 January 2016; Guest editor: Reiner Dohrmann)

\begin{abstract}
Compacted bentonite is to be used as a buffer material between waste canisters and the bedrock in the deep geological disposal of high-level nuclear waste in several countries. In spite of the fact that such large bentonite systems have long equilibration times, estimation of the material properties and performance in repository conditions is often based on short-term, laboratory-scale experiments. Sample-preparation procedures in these experiments may differ from the natural evolution of the bentonite in the repository, however, affecting the bentonite properties. The present study reports the influence on the structure of clay tactoids of four different preparation procedures of water-saturated, compacted MX-80 bentonite samples using four target dry bulk densities. Small-angle X-ray scattering was used to illustrate the differences between the samples. The different treatments of the bentonite samples may lead to different structural features. Clear differences between low-density samples prepared using different procedures were observed. The influence of the preparation methods was less, but still noticeable, for the high-density samples.
\end{abstract}

KeYwORDS: MX-80, bentonite, buffer, microstructure, repository conditions, small-angle X-ray scattering.

The MX-80 bentonite is considered as a possible material for clay buffers to be used in repositories for spent nuclear fuel, in countries such as Finland (Posiva, 2012; SKB, 2011). The long life expectancy of the repository, $>100,000 \mathrm{y}$, requires in-depth knowledge and understanding of the materials used in construction. Due to the uncontrollable conditions in real repository systems and to the long times needed for large bentonite systems to equilibrate, many properties of the MX-80 clay are estimated in small-scale laboratory experiments (Van Loon et al., 2003; Schatz et al., 2013). To obtain representative results from these experiments for the analysis of the whole repository it is important to fully control the experimental conditions and to understand the possible sources of errors and artefacts.

One possible problem in making the predictions needed for performance analysis of full-scale models

*E-mail: Michal.Matusewicz@vtt.fi

DOI: 10.1180/claymin.2015.051.2.06 (including both size and time) based on laboratory experiments, lies in sample preparation, which may bias the experimental results in numerous ways. For different samples in the same experimental series one problem might be the storage time between sample preparation and the measurement. Other problems may also become apparent, e.g. between different laboratory experimental series and, in particular, between different laboratories: the initial water content may vary significantly; saturation may be performed in many different ways; and the order between compaction and saturation may vary, etc.

Previous studies have reported the influence of sample preparation on the quality of the X-ray diffraction (XRD) patterns used for mineralogical analysis (e.g. Jonas \& Kuykendall, 1966; Bish \& Reynolds, 1989; Hillier, 1999; Kleeberg et al., 2008). Other authors have described the influence of sample preparation on the clay microstructure: the influence of grinding and impregnation of the samples on scanning electron microscope and X-ray diffraction studies was investigated by Barden \& Sides (1971). The evolution 
of the microstructure of the clay samples of different densities and with changes in water content with time were analysed by Delage et al. (2006). The XRD patterns of samples saturated from aqueous phase under confined and non-confined conditions and from the vapour phase under adsorption or desorption conditions were compared by Holmboe et al. (2012).

Previous studies of the influence of the microstructure on the diffusion parameters have focused mainly on the change of the structure induced by variation of clay density and ionic strength of the solution (Sato et al., 1992; Oscarson, 1994; Muurinen et al., 2004; Van Loon et al., 2007). Details of sample-preparation techniques were often not discussed.

In a study similar to the present one, Muurinen et al. (2007) investigated the change in the amount of chloride entering the pore space under different methods of sample preparation. Those authors varied the density of the clay material, the duration of saturation and the salinity of the saturating solution. Conclusions about the microstructure of bentonite were drawn based on the modelling of chloride concentrations. In the present study the influence of sample preparation on the structure of clay tactoids was investigated by comparing small-angle X-ray scattering (SAXS) analysis results using different dry bulk densities.

\section{MATERIALS AND METHODS}

Each of the four target dry bulk densities of the watersaturated samples was reached with four compactionwetting-swelling preparation paths. Two of the paths followed the natural evolution of the bentonite repository: the bentonite was compacted first to the installation dry bulk density from powder and then it was allowed to become wet and swell to the lower target density. The effect of the salinity of the wetting solution was studied using either MilliQ water or $0.1 \mathrm{M}$ $\mathrm{NaCl}$ saturating fluid solution. One path corresponded to the common sample-preparation procedure in which dry bentonite powder is compacted directly to the target density and is then saturated. The fourth path was unlike the others and the bentonite powder was first compacted to a high density, then it was saturated in confined volume and finally it was allowed to swell to the target density.

Using SAXS data the mean distance between the 2:1 layers in montmorillonite tactoids may be estimated. The different shape and intensity of the peaks imply, on average, different sizes and degrees of organization of the tactoids.
The MX- 80 bentonite (obtained from CETCO, UK) was used as received. MX- 80 is a Na-Ca-bentonite $(62 \%(\mathrm{Na})$ and $26 \%(\mathrm{Ca})$ of exchangeable sites) with a smectite content of 87 wt.\%. Detailed characterization of this material can be found in Kiviranta \& Kumpulainen (2011). The water-saturated samples were investigated at four target dry bulk densities: $0.7,1.0,1.3$ and $1.5 \mathrm{~g} / \mathrm{cm}^{3}$. Four different methods of sample preparation were tested (Fig. 1): (1) air-dried clay was compacted to the target density, if required, and was saturated with Milli-Q water in a confined volume. (2) Air-dried clay was compacted to $\sim 1.8 \mathrm{~g} /$ $\mathrm{cm}^{3}$, saturated with Milli-Q water and was allowed to swell to the target density. (3) Air-dried clay was compacted to $\sim 1.8 \mathrm{~g} / \mathrm{cm}^{3}$, saturated with $0.1 \mathrm{M} \mathrm{NaCl}$ solution and allowed to swell to the target density. (4) Milli-Q water-saturated clay at $1.6 \mathrm{~g} / \mathrm{cm}^{3}$ dry bulk density was allowed to swell to the target density.

Cylindrical samples ( $2 \mathrm{~cm}$ in diameter, $1 \mathrm{~cm}$ high) were placed in stainless steel equilibration cells. Contact with water or salt solution was ensured through sinters confining the bases of the pellets. Samples that required compaction were compacted uniaxially with pressure applied directly to the equilibration cells.

The equilibration time of the samples was between 45 and 55 days. Detailed sample information is presented in Table 1.

The samples for SAXS measurements were probed using a stainless steel cylindrical cutter $4 \mathrm{~mm}$ in diameter and were cut into $0.3 \mathrm{~mm}$ slices. Sample preparation was carried out in a chamber with controlled relative humidity of $\sim 80 \%$. Slices were enclosed in metal rings and were sealed tightly with a thin plastic film to prevent drying. To ensure that drying does not occur during the measurement, closed holders containing the samples were weighed before and after measurements. In addition, 30-min measurements were split into 5 min time blocks to check that XRD patterns did not change with time.

The X-rays were generated using an X-ray tube with Cu-anode (PANalytical, Almelo, the Netherlands). The X-ray beam was collimated and monochromated to $\mathrm{Cu}-\mathrm{K \alpha}$ radiation $(\lambda=1.5406 \AA)$ using a Montelmultilayer mirror. The scattered $\mathrm{X}$-rays were recorded using a Bruker Hi-Star area detector.

The SAXS patterns covered the angles $\theta$ corresponding to the scattering vector $q=4 \pi \sin (\theta / \lambda)$ range from 0.065 to $1.1 \AA^{-1}$. A silver behenate standard was used to calibrate the $q$ scale (Huang et al., 1993). The 2D intensity profiles were averaged spherically and corrected for absorption, detector geometry, air 


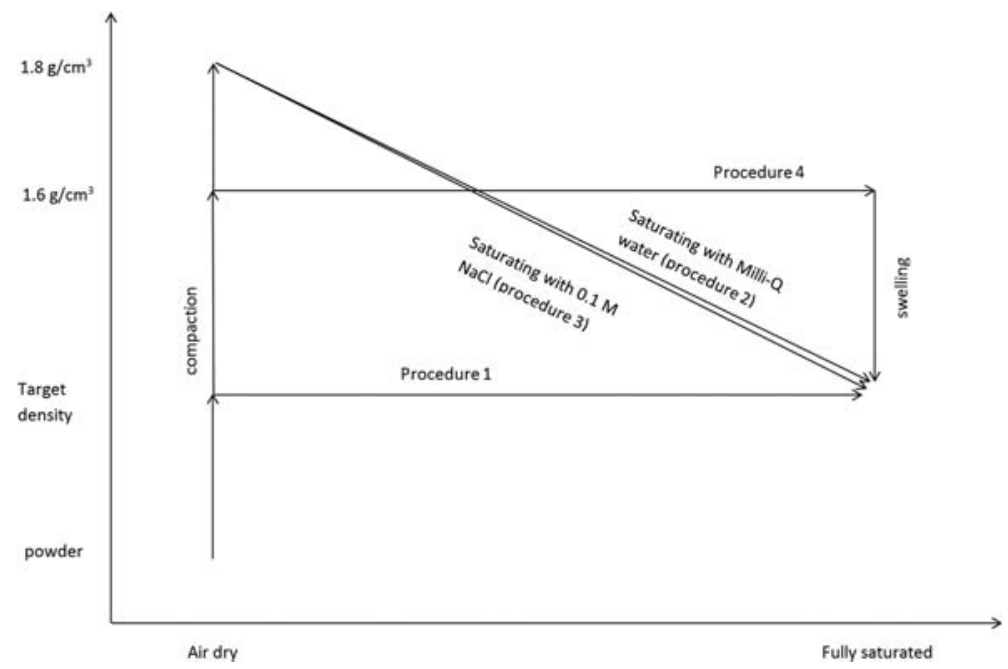

FIG. 1. Schematic representation of the sample-preparation procedures.

scattering and the Lorentz-polarization for randomly oriented powder (Moore \& Reynolds, 1997).

The average basal distance was calculated according to Muurinen et al. (2013). Briefly, the approach is based on the assumption that the scattering intensity at a given basal distance is proportional to the amount of the tactoids with that basal distance. In this way, the average basal distance does not have to correspond to the position of the peak maximum if the peak is formed by overlapping components. Peaks observed at distances

TABLE 1. Sample parameters used in the experiments.

\begin{tabular}{lcccc}
\hline Sample & Preparation procedure & $\begin{array}{c}\text { Dry bulk } \\
\text { density }\left(\mathrm{g} / \mathrm{cm}^{3}\right)\end{array}$ & $\begin{array}{c}\text { Equilibration } \\
\text { time (days) }\end{array}$ & $\begin{array}{c}\text { Average basal } \\
\text { spacing }(\AA)\end{array}$ \\
\hline F10 & Not compacted (1) & 0.75 & 44 & 20.3 \\
F11 & Swelling from dry, compacted (2) & 0.72 & 44 & 20.0 \\
G2 & Swelling from dry, compacted, & 0.67 & 57 & 19.9 \\
F12 & NaCl (3) & 0.71 & $26+18$ & 20.7 \\
G3 & Swelling from wet, compacted (4) & 0.93 & 56 & 19.9 \\
G12 & Not compacted (1) & 0.94 & 52 & 19.8 \\
G13 & Swelling from dry, compacted (2) & 0.96 & 52 & 19.7 \\
G4 & Swelling from dry, compacted, & & \\
G11 & NaCl (3) & 0.99 & $46+21$ & 19.6 \\
G9 & Swelling from wet, compacted (4) & 1.22 & 52 & 19.6 \\
G10 & Compacted to target density (1) & 1.24 & 52 & 19.5 \\
G5 & Swelling from dry compacted (2) & 1.26 & 52 & 19.4 \\
G6 & Swelling from dry, compacted, & NaCl (3) & $45+21$ & 17.9 \\
G7 & Swelling from wet, compacted (4) & 1.28 & 54 & 18.3 \\
G8 & Compacted to target density (1) & 1.56 & 53 & 18.1 \\
& Swelling from dry, compacted (2) & 1.51 & 53 & \\
\hline
\end{tabular}


of $>35 \AA$ were not included in the calculation of the average basal distance.

\section{RESULTS}

At the lowest target dry bulk density investigated, $0.7 \mathrm{~g} / \mathrm{cm}^{3}$, all the scattering curves displayed different features (Fig. 2). Samples swelling from the dry, compacted state (preparation procedures 2 and 3 described in the previous section) have very similar peak shapes, but clearly differ in the Porod region, towards smaller scattering angles from the main scattering peak (001) at $\sim 20 \AA$. The third sample swelling from dry conditions (preparation procedure 1) also has a similar peak shape, differing only by a more pronounced decrease of the scattering intensity on the side of wider scattering angles. Compacted samples swelling in contact with water (procedures 2 and 4) are very similar in the Porod region but have different peak shapes. The sample swelling from the wet compacted state (procedure 4) has the lowest and the broadest (001) peak of all the samples of this density. All the samples display a very wide peak at $\sim 0.1-0.17 \AA^{-1}$ (37-63 $\AA$ ), in accordance with previous studies (Norrish, 1954; Muurinen, 2009; Segad et al., 2010).

Clear variations in the scattering curves were also observed at the target dry bulk density of $\sim 1.0 \mathrm{~g} / \mathrm{cm}^{3}$ (Fig. 3). All the compacted samples (procedures 2, 3, 4) have similar shapes in terms of the 001 peak.
Samples G4 and G13 (procedures 3 and 4) also have a similar Porod region. Similar to the $0.7 \mathrm{~g} / \mathrm{cm}^{3}$ samples, all of the $1.0 \mathrm{~g} / \mathrm{cm}^{3}$ samples have a very broad peak between 0.12 and $0.19 \AA^{-1}$, which is less pronounced in the denser samples, however.

All samples with a target dry bulk density of $\sim 1.3 \mathrm{~g} / \mathrm{cm}^{3}$ have remarkably similar scattering patterns (Fig. 4). A very broad, low-intensity peak can still be seen at $0.14-0.20 \AA^{-1}$ and a symmetrical, intense peak is visible at $0.33 \AA^{-1}$.

The scattering curves of the samples with a target dry bulk density of $\sim 1.5 \mathrm{~g} / \mathrm{cm}^{3}$ are shown in Fig. 5. All samples are similar in the Porod region, but differ slightly in the peak region where two overlapping peaks corresponding to 0.34 and $0.39 \AA^{-1}$ (basal spacing $\approx 18.5$ and $16.5 \AA$, respectively) occur. The sample compacted to the target density (procedure 1) has the most pronounced peak corresponding to the wider scattering angle, which could be attributed to the difference in dry bulk density $-1.56 \mathrm{~g} / \mathrm{cm}^{3}$ compared to 1.51 and $1.50 \mathrm{~g} / \mathrm{cm}^{3}$ for the remaining samples. Swelling of the samples from the dry compacted state (procedures 2 and 3 ) yields a more intense peak at $0.39 \AA^{-1}$ compared to the sample saturated with $\mathrm{NaCl}$ solution (procedure 3 ).

The change in calculated average basal spacing as a function of dry bulk density is illustrated in Fig. 6 . Only small variations between the samples of similar density are observed in general. The most pronounced

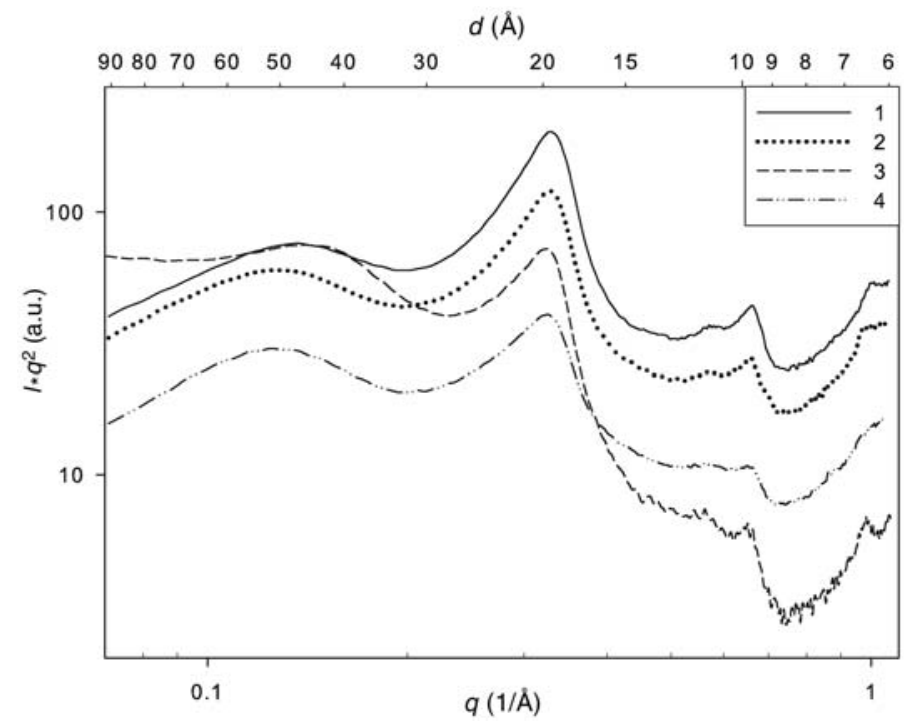

FIG. 2. X-ray scattering curves of the samples at $0.7 \mathrm{~g} / \mathrm{cm}^{3}$ dry bulk density. The numbers in the legend correspond to the preparation procedures as marked in Table 1. 


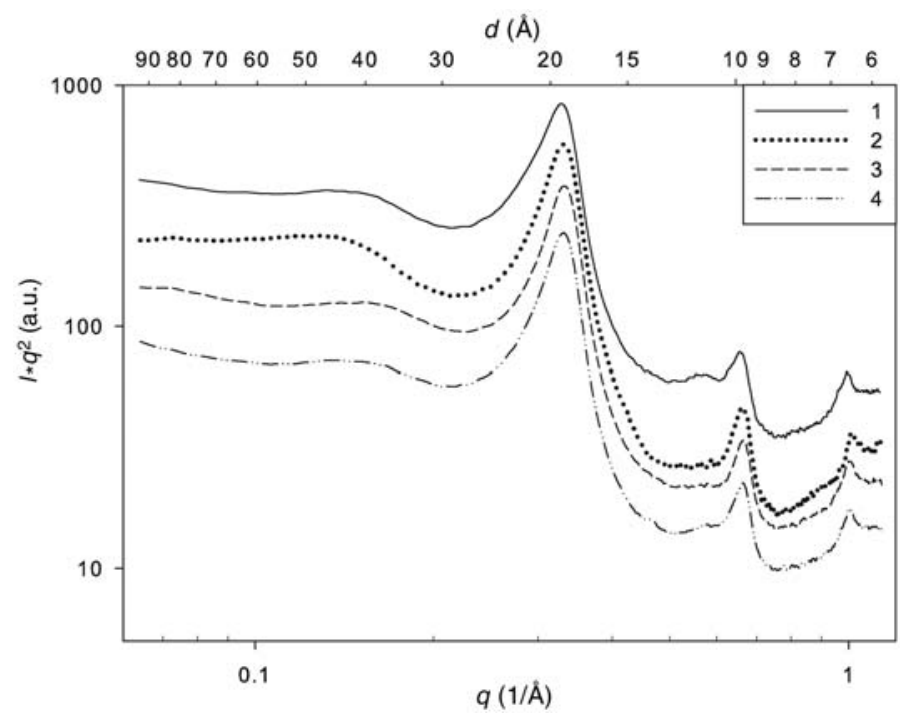

FIG. 3. X-ray scattering curves of the samples at $1.0 \mathrm{~g} / \mathrm{cm}^{3}$ dry bulk density. The numbers in the legend correspond to the preparation procedures as marked in Table 1 .

differences occur for samples at the $0.7 \mathrm{~g} / \mathrm{cm}^{3}$ dry bulk density. The sample saturated with $0.1 \mathrm{M} \mathrm{NaCl}$ solution (procedure 3) clearly has a smaller average basal spacing, in agreement with previous work (Svensson \& Hansen, 2013).

\section{DISCUSSION}

The sample-preparation procedure will alter the in situ structure of a wet, compacted sample in confined conditions. Upon opening of the saturation cell the sample is not constrained and stress is released by

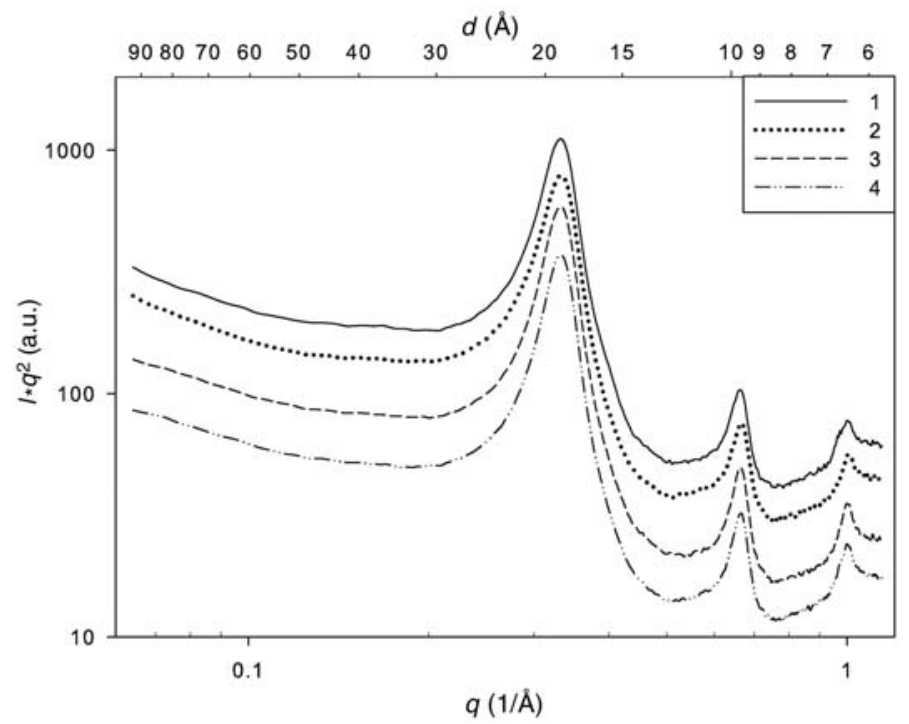

FIG. 4. X-ray scattering curves of the samples at $1.3 \mathrm{~g} / \mathrm{cm}^{3}$ dry bulk density. The numbers in the legend correspond to the preparation procedures as marked in Table 1. 


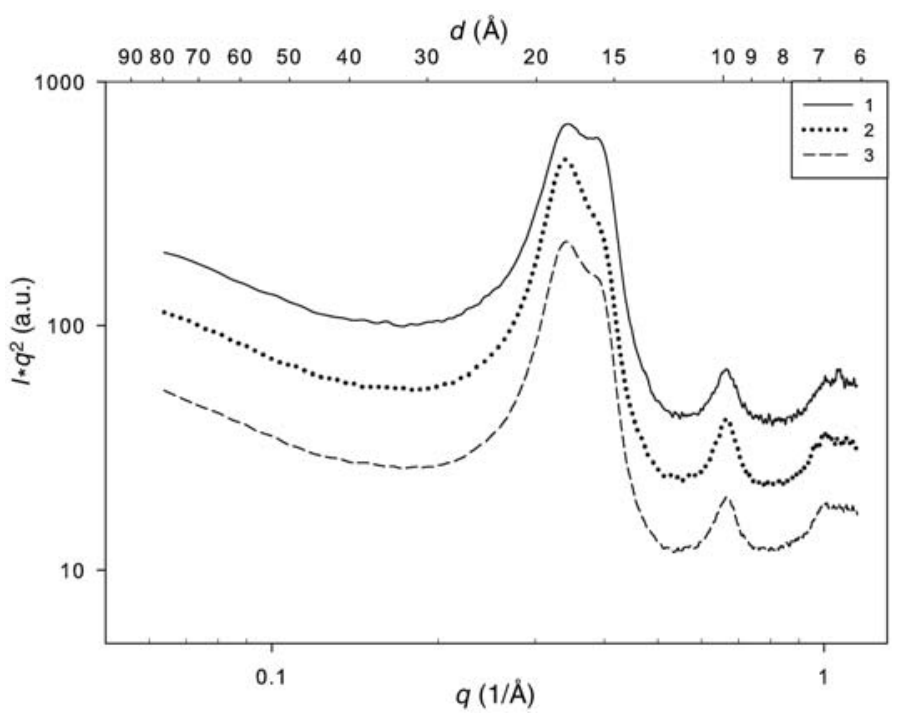

FIG. 5. X-ray scattering curves of the samples at $1.5 \mathrm{~g} / \mathrm{cm}^{3}$ dry bulk density. The numbers in the legend correspond to the preparation procedures as marked in Table 1 .

limited swelling. Cutting the clay into thin slices is likely to induce shearing effects. The short exposure to the $80 \%$ relative humidity atmosphere in the humidity chamber will not be able to prevent completely capillary drying (Cases et al., 1992), and can only aim to minimize the loss of water. After opening the saturation cells, all the samples in the present study were treated in exactly the same way. This allowed us to compare the influence of the different pathways of clay compaction and saturation on the samples structure.

The low-density samples have pronounced peaks corresponding to larger distances, $\sim 40-50 \AA$, which might originate from the structures resulting from an

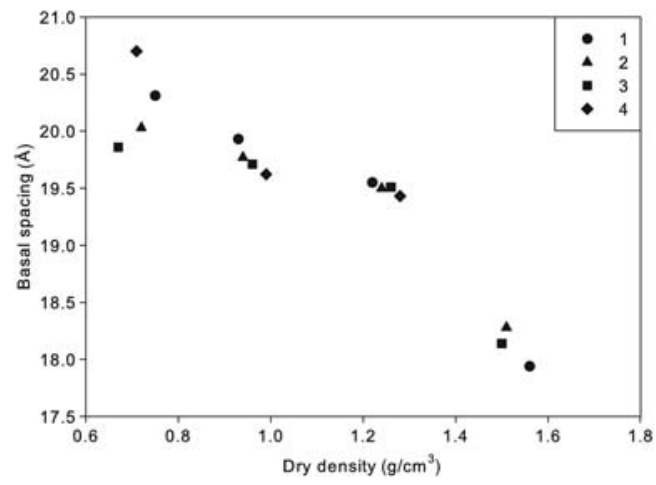

FIG. 6. Average basal spacing as a function of dry bulk density. osmotic swelling process. With increase in the sample density, the intensity of the peaks decreased and their maxima were shifted towards smaller distances. The shape of the peaks also varied between the samples prepared with different preparation procedures, but the present study does not provide sufficient evidence to come to any firm conclusions about this relationship.

The splitting of the main diffraction peak for highdensity samples (Fig. 5) into two components corresponds to the transition from the average of three water layers to two water layers in the interlamellar space. However, the 001 peak observed might also consist of a number of components in the case of lower densities (Laird, 2006).

Different treatment of the MX- 80 bentonite samples might lead to different structural features which might influence the properties of the bentonite, e.g. in diffusion experiments. The present study has shown clearly the effect of sample preparation on the microstructure (X-ray scattering peak positions) of specimens with dry bulk densities of $0.7,1.0$ and $1.5 \mathrm{~g} / \mathrm{cm}^{3}$. No significant influence on the samples of dry bulk density $1.3 \mathrm{~g} / \mathrm{cm}^{3}$ was observed, however. Differences appeared again for the samples with dry bulk density of $1.5 \mathrm{~g} / \mathrm{cm}^{3}$, however. No clear relationship between the sample-preparation procedure used and the observed differences in the scattering curves was observed throughout the investigated density range.

The equilibration time of the samples in this experiment was 45-55 days, whereas Delage et al. 
(2006) observed structural changes between the samples equilibrating for 10 and 90 days. Further systematic research is necessary to link and characterize the relationships between different preparation procedures and resulting differences in the clay microstructure.

\section{ACKNOWLEDGEMENTS}

The research leading to these results received funding from the European Atomic Energy Community's Seventh Framework Programme (FP7/2007-2011) under Grant Agreement $n^{\circ} 295487$, the BELBaR project. The SAXS measurements were performed at the Department of Physics at the University of Helsinki. Ville Liljeström is kindly acknowledged for fruitful discussions. Finally, the authors thank the reviewers for their insightful comments.

\section{REFERENCES}

Barden L. \& Sides G. (1971) Sample disturbance in the investigation of clay structure. Geotechnique, 21, 211-222.

Bish D.L. \& Reynolds R. (1989) Sample preparation for X-ray diffraction. Pp. 73-99 in: Modern Powder Diffraction (D.L. Bish and J.E. Post, editors). Reviews in Mineralogy, 20, Mineralogical Society of America, Washington D.C.

Cases J., Bérend I., Besson G., Francois M., Uriot J., Thomas F. \& Poirier J. (1992) Mechanism of adsorption and desorption of water vapor by homoionic montmorillonite. 1. The sodium-exchanged form. Langmuir, 8, 2730-2739.

Delage P., Marcial D., Cui Y. \& Ruiz X. (2006) Ageing effects in a compacted bentonite: a microstructure approach. Géotechnique, 56, 291-304.

Hillier S. (1999) Use of an air brush to spray dry samples for X-ray powder diffraction. Clay Minerals, 34, $127-135$

Holmboe M., Wold S. \& Jonsson M. (2012) Porosity investigation of compacted bentonite using XRD profile modeling. Journal of Contaminant Hydrology, 128, 19-32.

Huang T.C., Toraya H., Blanton T.N. \& Wu Y. (1993) $\mathrm{X}$-ray powder diffraction analysis of silver behenate, a possible low-angle diffraction standard. Journal of Applied Crystallography, 26, 180-184.

Jonas E.C. \& Kuykendall J.R. (1966) Preparation of montmorillonites for random powder diffraction. Clay Minerals, 6, 232-235.

Kiviranta L. \& Kumpulainen S. (2011) Quality control and characterization of bentonite materials. Working Report 2011-84, Posiva Oy, Eurajoki.

Kleeberg R., Monecke T. \& Hillier S. (2008) Preferred orientation of mineral grains in sample mounts for quantitative XRD measurements: how random are powder samples? Clays and Clay Minerals, 56, 404-415.

Laird D.A. (2006) Influence of layer charge on swelling of smectites. Applied Clay Science, 34, 74-87

Moore D.M. \& Reynolds R.C. (1997) X-ray Diffraction and the Identification and Analysis of Clay Minerals. Oxford University Press, New York.

Muurinen A. (2009) Studies on the Chemical Conditions and Microstructure in the Reference Bentonites of Alternative Buffer Materials Project (ABM) in Äspö. Working Report 2009-42, Posiva OY, Eurajoki.

Muurinen A., Karnland O. \& Lehikoinen J. (2004) Ion concentration caused by an external solution into the porewater of compacted bentonite. Physics and Chemistry of the Earth, Parts $A / B / C, 29,119-127$

Muurinen A., Karnland O. \& Lehikoinen J. (2007) Effect of homogenization on the microstructure and exclusion of chloride in compacted bentonite. Physics and Chemistry of the Earth, Parts $A / B / C, 32,485-490$

Muurinen A., Carlsson T. \& Root A. (2013) Bentonite pore distribution based on SAXS, chloride exclusion and NMR studies. Clay Minerals, 48, 251-266

Norrish K. (1954) The swelling of montmorillonite. Discussions of the Faraday Society, 18, 120-134

Oscarson D.W. (1994) Surface diffusion: Is it an important transport mechanism in compacted clays? Clays and Clay Minerals, 42, 534-543.

Posiva (2012) YJH 2012, Nuclear Waste Management at Olkiluoto and Loviisa Power Plants: Review of Current Status and Future Plans for 2013-2015. YJH-2012, Posiva OY, Eurajoki.

Sato H., Ashida T., Kohara Y., Yui M. \& Sasaki N. (1992) Effect of dry density on diffusion of some radionuclides in compacted sodium bentonite. Journal of Nuclear Science and Technology, 29, 873-882

Schatz T., Kanerva N., Martikainen J., Sane P., Olin M., Seppälä A. \& Koskinen K. (2013) Buffer erosion in dilute groundwater. Posiva 2012-44, Posiva Oy, Eurajoki.

Segad M., Jönsson B., Åkesson T. \& Cabane B. (2010) $\mathrm{Ca} / \mathrm{Na}$ montmorillonite: Structure, forces and swelling properties. Langmuir, 26, 5782-5790

SKB (2011) Long-term safety for the final repository for spent nuclear fuel at Forsmark. TR-11-01, Svensk Kärnbränslehantering AB, Stockholm.

Svensson P.D. \& Hansen S. (2013) Combined salt and temperature impact on montmorillonite hydration. Clays and Clay Minerals, 61, 328-341

Van Loon L., Soler J., Jakob A. \& Bradbury M. (2003) Effect of confining pressure on the diffusion of HTO, ${ }^{36} \mathrm{Cl}^{-}$and ${ }^{125} \mathrm{I}^{-}$in a layered argillaceous rock (Opalinus Clay): diffusion perpendicular to the fabric. Applied Geochemistry, 18, 1653-1662

Van Loon L.R., Glaus M.A. \& Müller W. (2007) Anion exclusion effects in compacted bentonites: towards a better understanding of anion diffusion. Applied Geochemistry, 22, 2536-2552 